\title{
O SETOR FINANCEIRO NACIONAL POSSUI PODER DE MERCADO (MARK-UPS) SUPERIOR AO SETOR INDUSTRIAL DA ECONOMIA BRASILEIRA?
}

Eric Jardim ${ }^{1}$

\section{SINOPSE}

Há uma recorrente discussão na economia brasileira de que os diferenciais entre os custos de captação de recursos e os custos de empréstimos concedidos praticados no Sistema Financeiro Nacional (SFN) sáo elevados em decorrência da prática da formação de preços dos serviços financeiros por meio de excessivo exercício do poder de mercado dos bancos, e que as margens de receitas dos bancos em relação aos seus custos são expressivamente mais altas em comparação às demais atividades econômicas brasileiras. Este texto visa explorar técnicas de mensuração do diferencial entre as margens de resultado da atividade financeira em relação aos seus custos por meio da metodologia de mark-ups apresentada por Jan De Loecker e Frederic Warzynski. Além disso, avalia-se aqui se algumas empresas que compóem o SFN, sobretudo as de intermediação e concessão de créditos, possuem uma estrutura de relação de preços e custos que são discrepantes de demais atividades da economia, em particular o setor industrial brasileiro.

Palavras-chave: mark-up; spread bancário; concentração bancária; poder de mercado.

DOI: http://dx.doi.org/10.38116/radar63art6.

\section{INTRODUÇÃO}

A introdução do Plano Real na década de 1990 induziu o setor financeiro privado brasileiro a uma crise, visto que grande parte das receitas e do desempenho econômico era obtida mediante a arbitragem de ativos em um contexto de hiperinflação. No setor público, inúmeros bancos estaduais passaram por privatizaçôes ou reestruturaçôes. Os governos estaduais adotavam a prática de utilizar esses bancos para financiar seus orçamentos, frequentemente descumprindo os compromissos de devolução desses recursos aos bancos. A necessidade de socorro e intervenção dos órgãos reguladores, sobretudo do Banco Central do Brasil (BCB), foi intensa nesse período. Em decorrência dos programas aplicados - Programa de Estímulo à Reestruturação e ao Fortalecimento do Sistema Financeiro Nacional (PROER), Programa de Incentivo à Redução do Setor Público Estadual na Atividade Bancária (PROES) etc. -, um grande processo de liquidação e concentração bancária se iniciou e prosseguiu, e pôde ser visto até muitos anos depois, uma vez que uma nova onda ocorreu em decorrência da crise financeira internacional de 2008. Acredita-se que todos esses fenômenos construíram um sistema financeiro oligopolizado que exerce práticas de mercado abusivas, em termos de elevados spreads e taxas de lucro.

Buscando entender se de fato as margens de preço e custo das empresas de intermediação de crédito que atuam no setor financeiro brasileiro apresentam características discrepantes de outras atividades econômicas, foi selecionada para avaliação uma metodologia de cálculo de efeitos de poder de mercado para replicá-la às

1. Pesquisador do Programa de Pesquisa para o Desenvolvimento Nacional (PNPD) na Diretoria de Estudos e Políticas Setoriais de Inovação e Infraestrutura (Diset) do Ipea. 
empresas do setor financeiro brasileiro, sobretudo às instituiçóes bancárias. Para efeitos de comparação, o setor industrial (manufatureiro e extrativo) foi considerado contraparte de observação, visto que este é um dos setores da sociedade que recorrentemente se apresentam como críticos às práticas dos preços e produtos do setor financeiro e alegam que essas empresas praticam poder de mercado elevado com mark-ups demasiadamente altos.

Os resultados aqui obtidos são avaliaçóes iniciais e preliminares de um estudo mais abrangente que está em desenvolvimento e que avaliará o poder de mercado em setores desagregados da economia brasileira de maneira mais aprofundada.

\section{DISCUSSÃO}

A concentração dos agentes bancários permite que o sistema financeiro ganhe robustez, escala e eficiências tecnológicas superiores. Diversos estudos apontam que essa é uma consequência decorrente da consolidação de empresas desse setor - pelo menos para países desenvolvidos -, cabendo aqui citar Berger et al. (2007), que testaram duas hipóteses motivacionais para a concentração bancária nos Estados Unidos: a de ganhos de escala (tecnológica) contra a de pura arrogância (hubris) dos executivos dos bancos na busca de crescimento predatório no mercado. Seus resultados corroboram a hipótese de geração de eficiência como motivação para a concentração bancária nos Estados Unidos. Os ganhos de eficiência vieram, sobretudo, pelo aumento de economias de escala oriundas da tecnologia, que otimizou o gerenciamento de informaçóes por meio do aprimoramento das telecomunicaçóes e permitiu o avanço de finanças avançadas aplicadas na diversificação de carteiras e na montagem de operaçóes com estruturas de risco minimizadas.

Para o caso brasileiro, muitos estudos verificaram as mesmas hipóteses. Os resultados de Faria, Paula e Marinho (2006), com a aplicação da técnica de análise envoltória de dados (data envelopment analysis - DEA), mostram que houve uma melhora na eficiência de intermediação para todos os grandes bancos privados no processo de consolidação da década de 2000, e dois bancos privados ${ }^{2}$ apresentaram melhora na eficiência de resultados com a ampliação de suas participaçóes de mercado via fusóes e aquisiçóes. Dantas, Medeiros e Paulo (2011) avaliaram o efeito da concentração na rentabilidade do setor bancário brasileiro e concluíram que o aumento da concentração de mercado não explicou uma maior rentabilidade das instituições financeiras brasileiras, mas, sim, produziu uma estrutura bancária mais eficiente.

Cardoso, Azevedo e Barbosa (2017) avaliaram os efeitos do poder de mercado sobre a oferta dos empréstimos bancários. Eles partiram da hipótese de que uma redução da oferta seria diretamente proporcional ao aumento do mark-up dos bancos, que, por sua vez, seria decorrente de práticas de preços superiores, características da suposta oligopolização deste mercado. Os autores chegaram à conclusão de que o aumento da participação de mercado (market share) de um conglomerado financeiro estava associado a um aumento mais que proporcional da oferta de empréstimos bancários, e que isso estava diretamente associado a mecanismos de eficiências de escala. Entretanto, os autores também ressaltaram que o impacto na oferta de crédito seria atenuado se o nível de concorrência do mercado bancário fosse mais baixo.

A despeito, contudo, de diversas evidências de que o setor financeiro brasileiro náo atua de maneira abusiva, inúmeros setores da sociedade questionam as taxas de lucro e os preços nele praticados. Esta percepção se dá em grande parte porque por muito tempo as taxas de juros reais foram elevadas no Brasil, assim como os spreads cobrados no SFN. O spread depende de diversos componentes, como o custo de captação, a taxa de inadimplência, a segurança jurídica na execução de contratos e garantias e também a taxa de lucro. No entanto, programas de resgates com recursos públicos como o PROER e o fluxo de renda do governo para as empresas

2. São eles: Bradesco e Itaú. 
do SFN em decorrência do financiamento à dívida pública geram a sensação de que o SFN é um empecilho ao desenvolvimento do país.

Ao fazer a comparação de uma medida de poder de mercado de empresas do setor bancário brasileiro com outros setores da economia, é possível evidenciar que não há práticas de poder de mercado (mark-ups) elevadas nas empresas do setor financeiro do Brasil. Por isso, este estudo apresenta resultados iniciais comparativos entre medidas de mark-ups dos setores bancário e industrial e tece algumas consideraçóes.

\section{METODOLOGIA}

A metodologia utilizada para estimar o poder de mercado (mark-up) das empresas é decorrente de um método empregado em De Loecker e Warzynski (2009). A abordagem tem como pressuposto primordial as condiçóes gerais de primeira ordem de minimização de custos da firma e uma função de produção que associa o produto da firma como a combinação de três insumos observáveis e um não observável: capital, trabalho, materiais (bens intermediários) e produtividade total dos fatores, respectivamente.

Para calcular o mark-up utilizam-se apenas a elasticidade do insumo variável, que seja plenamente flexível no processo de produção, e a informação sobre a proporção do custo desse insumo na receita total. O insumo variável plenamente flexível é eleito para o cálculo por refletir mais adequadamente a liberdade do empresário em arbitrar na produção, sem muitos custos de transação. Num mercado oligopolista, qualquer decisão de produção afeta o nível de preços. Empresas que buscam exercer poder de mercado ou mark-ups elevados, ou seja, se apropriar de receitas que excedem o custo marginal, o fazem utilizando os insumos sobre cujos custos elas tenham controle e certa liberdade instantânea para manipular. Fatores de produção como capital e trabalho não se enquadram nesse quesito, pois têm prazo de maturação, de fornecimento, ou rigidez contratual e custos legais para fazer modificações em seus níveis.

Foram utilizadas três bases de dados principais para a obtenção dos valores para as regressóes: a Pesquisa Industrial Anual-Empresa (PIA-Empresa), do Instituto Brasileiro de Geografia e Estatística (IBGE), para as empresas das indústrias extrativas e indústrias de transformação; a Relação Anual de Informações Sociais (RAIS), do Ministério da Economia, para as informaçôes sobre salários e número de empregados; e o Plano Contábil das Instituiçóes Financeiras (COSIF), regulado e disponibilizado pelo BCB. O período de análise foi de 2000 a 2017 para o caso das empresas industriais oriundas da PIA-Empresa; para os saldos contábeis, o valor do saldo no mês de dezembro de 2000 a 2017, no caso das instituiçóes do SFN reguladas pelo BCB.

As variáveis utilizadas para a estimação dos mark-ups estão descritas a seguir.

- $Q_{i t}$ : valor bruto da produção para as empresas da indústria; e valor das receitas operacionais e náo operacionais das empresas no COSIF (contas 71000008 e 73000006 ) para as empresas do setor financeiro. Os valores foram deflacionados setorialmente pelo Índice de Preços por Atacado-Oferta Global (IPA-OG) da Fundação Getulio Vargas (FGV), no caso das primeiras, e pelo Índice Geral de Preços-Disponibilidade Interna (IGP-DI), no caso das últimas.

- $L_{i t}$ : pessoal ocupado em número de trabalhadores.

- $K_{i t}$ : estoque de capital, conforme Alves e Silva (2008), para as empresas da indústria; e conta de ativo permanente no COSIF (conta 20000004) para as empresas do setor financeiro. Ambos deflacionados pelo índice de preços obtido por meio da razão do índice anual de valor da formação bruta de capital fixo do IBGE e do índice anual de quantidade da formação bruta de capital fixo do IBGE.

- $X_{i t}^{V}$ : consumo intermediário de materiais (custo operacional) das empresas industriais (inclui matérias-primas, eletricidade, combustíveis etc.); e despesas operacionais e não operacionais no COSIF (contas 81000005 
e 83000003), deduzidos os gastos com pessoal, para as empresas do setor financeiro (incluem gastos com telecomunicaçóes, aluguéis de espaço, material de escritório etc.). Estas variáveis foram deflacionadas pelo índice de bens intermediários que compóe o Índice de Preços por Atacado segundo Estágios de Processamento (IPA-EP) da FGV, no caso das empresas do setor industrial, e foi utilizado o IGP-DI da FGV para as empresas do setor financeiro.

\section{RESULTADOS}

Os resultados para a indústria foram obtidos a partir de um painel não balanceado de 639.710 observações, contendo 95.619 empresas industriais distintas. Para o setor financeiro, foi utilizado um painel não balanceado com 2.876 observaçóes referentes a 258 bancos distintos.

As funções de produção variaram de acordo com os diferentes setores a dois dígitos da Classificação Nacional de Atividades Econômicas (CNAE), para poder captar diferenças de tecnologia, mas os resultados são apresentados de forma agregada para a indústria. Para o setor financeiro, a função de produção considerou apenas a receita dos bancos conforme classificação no COSIF.

O gráfico 1 mostra a média simples das estimativas de mark-up para o período de 2000 a 2017 para o setores industrial e bancário brasileiros.

\section{GRÁFICO 1}

Brasil: mark-ups estimados para os setores industrial e bancário (2000-2017)

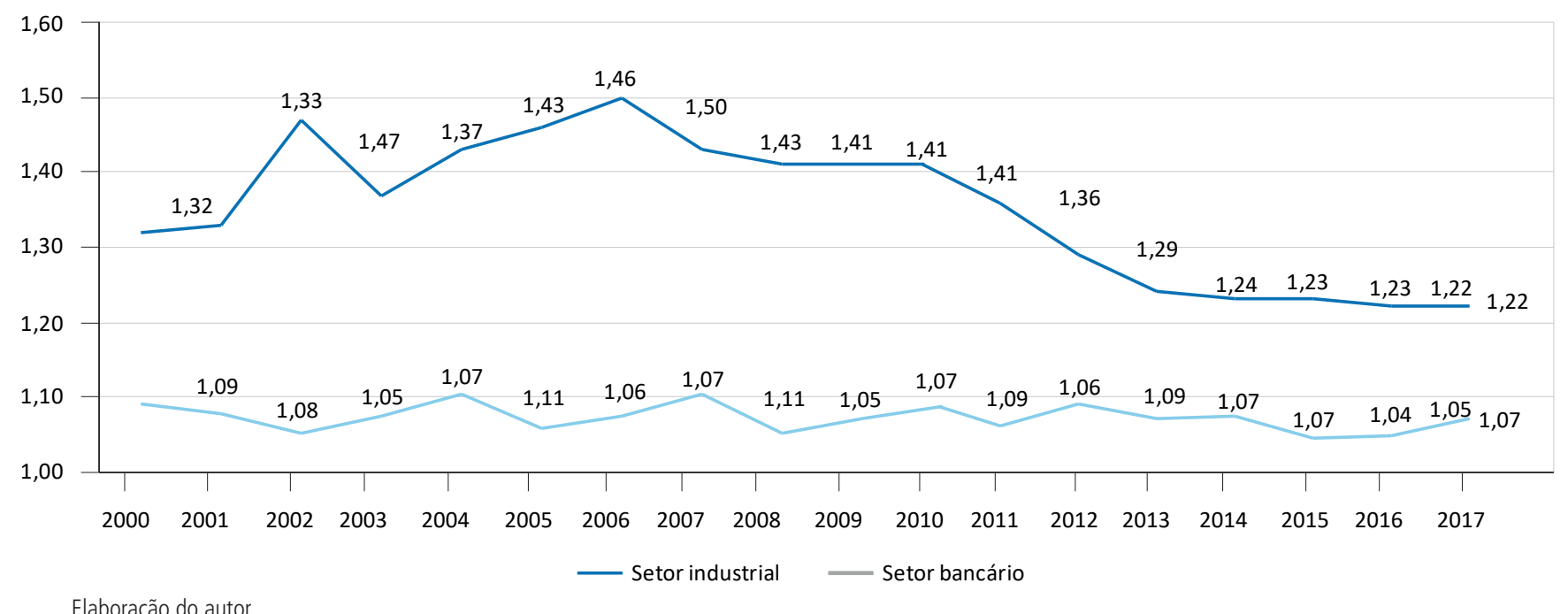

Elaboração do autor.

Os dados estimados demonstram que, para o período 2000-2017, o setor financeiro brasileiro, em especial o bancário, não praticou mark-ups elevados, sendo seus valores entre 4\% e 11\%. Já os mark-ups do setor industrial apresentaram patamares entre 22\% e 50\% acima de seus custos marginais. Embora mais alto, o mark-up industrial possui uma trajetória de queda no início do período e estabilidade na segunda metade do período.

Esses dados trazem uma nova perspectiva em relação aos constantes questionamentos que parte das empresas do sistema financeiro brasileiro sofre acerca das práticas dos preços de seus serviços. Entretanto, muito da estrutura de preços desse setor não necessariamente decorre de prática de exercício de poder de mercado (mark-ups elevados) e/ou ganância de seus gerentes ou acionistas, mas provavelmente da estrutura de custos das fontes de funding de suas atividades. 


\section{CONCLUSÕES}

Os resultados do trabalho evidenciam que o setor financeiro brasileiro não passou por um processo de imposição de poder de mercado e prática de mark-ups superiores a outras atividades da economia brasileira, particularmente o setor industrial. Pelo contrário, o setor industrial é que parece apresentar o dobro do mark-up que as empresas de intermediação bancária do SFN. O processo de concentração do período recente e a ampliação de market share em poucos grandes bancos não demonstram práticas de preços muito acima dos custos de produção da atividade financeira.

Entretanto, a atual metodologia encontra suas limitaçóes, sobretudo por se tratar de um setor tão específico quanto o bancário. Há uma longa discussão sobre como se caracteriza a produção (output) das empresas do setor financeiro, e a abordagem utilizada foi pela visão da intermediação financeira, que é apenas uma das modalidades de verificação da produção dessas empresas. Esse é o procedimento que encontra maior aderência em análise comparativa intersetorial.

O próximo passo pode estar em estimar esses mesmos mark-ups considerando as empresas do setor financeiro como agentes num espectro mais amplo da produção econômica, levando em conta não apenas as receitas como fruto da atividade de intermediação financeira, mas também os seus outros serviços, como a guarda patrimonial (dos próprios depósitos bancários colocados no banco como segurança), a criação de moeda e outros aspectos implícitos da atividade financeira.

A crítica acerca dos patamares dos spreads bancários no Brasil pode não estar relacionada com práticas de poder de mercados oligopolistas por parte dos bancos brasileiros. Outros fatores podem influenciar os custos dos produtos de tal maneira que o repasse aos consumidores cause a impressão de que as margens de preço dos bancos são elevadas. As medidas para influenciar a queda dos preços dos serviços financeiros residem em açôes que diminuam os custos da produção financeira, como a redução dos compulsórios, na queda da taxa básica de juros, no aumento da concorrência bancária com permissão para as pessoas contratarem empréstimos em bancos em contas estrangeiras, no estímulo a novas formas de obtenção de funding, na segurança jurídica na execução de garantias, entre outras.

O cadastro positivo também parece ser um passo inicial interessante para ajudar a reduzir os spreads e melhorar os componentes do custo do crédito que influenciam a formação dos preços dos serviços financeiros.

\section{REFERÊNCIAS}

ALVES, P.; SILVA, A. M. Estimativa do estoque de capital das empresas industriais brasileiras. Brasília: Ipea, 2008.

BERGER, A. N. et al. Competition from large, multimarket firms and the performance of small, single market firms: evidence from the banking industry. Journal of Money, Credit and Banking, v. 39, n. 2/3, p. 331-368, 2007.

CARDOSO, M.; AZEVEDO, P.; BARBOSA, K. Poder de mercado e nível de competiçáo no mercado de empréstimo brasileiro. [s.l.]: Insper, 2017. (Working Paper, n. 374).

DANTAS, J. A.; MEDEIROS, O. R. de; PAULO, E. Relação entre concentração e rentabilidade no setor bancário brasileiro. Revista Contabilidade e Finanças, v. 22, n. 55, p. 5-28, 2011.

DE LOECKER, J.; WARZYNSKI, F. Markups and firm-level export status. Cambridge, Massachusetts: NBER, 2009. (Working Paper, n. w15198). Disponível em: <https://ssrn.com/abstract=1442663>.

FARIA, J. A. de; PAULA, L. F. de; MARINHO, A. Fusóes e aquisiçóes bancárias no Brasil: uma avaliação da eficiência técnica e de escala. Rio de Janeiro: Ipea, 2006. 


\section{BIBLIOGRAFIA COMPLEMENTAR}

DE LOECKER, J.; WARZYNSKI, F. Markups and firm-level export status. American Economic Review, v. 102, n. 6, p. 2437-2471, 2012.

LEVINSOHN, J.; PETRIN, A. Estimating production functions using inputs to control for unobservables. The Review of Economic Studies, v. 70, n. 2, p. 317-341, 2003.

NAKANE, M. I.; ROCHA, B. Concentração, concorrência e rentabilidade no setor bancário brasileiro: uma visão atualizada. [s.l.]: Tendências Consultoria Integrada, 2010.

SMANIOTTO, E. N.; ALVES, T. W. Concentração e poder de mercado no sistema bancário brasileiro: uma análise pós-Plano Real. Perspectiva Econômica, v. 12, n. 1, p. 29-41, 2016. 
